\title{
Aerobic Fitness and Response Variability in Preadolescent Children Performing a Cognitive Control Task
}

\author{
Chien-Ting Wu, Matthew B. Pontifex, Lauren B. Raine, Laura Chaddock, Michelle W. Voss, \\ Arthur F. Kramer, and Charles H. Hillman \\ University of Illinois at Urbana-Champaign
}

\begin{abstract}
Objective: To investigate the relationship between aerobic fitness and cognitive variability in preadolescent children. Method: Forty-eight preadolescent children (25 males, 23 females, mean age $=10.1$ years) were grouped into higher- and lower-fit groups according to their performance on a test of aerobic capacity $\left(\mathrm{VO}_{2 \max }\right)$. Cognitive function was measured via behavioral responses to a modified flanker task. The distribution in reaction time was calculated within each participant to assess intraindividual variability of performance. Specifically, the standard deviation and coefficient variation of reaction time were used to represent cognitive variability. Results: Preadolescent children, regardless of fitness, exhibited longer reaction time, increased response variability, and decreased response accuracy to incongruent compared to congruent trials. Further, higher-fit children were less variable in their response time and more accurate in their responses across conditions of the flanker task, while no group differences were observed for response speed. Conclusion: These findings suggest that fitness is associated with better cognitive performance during a task that varies cognitive control demands, and extends this area of research to suggest that intraindividual variability may be a useful measure to examine the relationship between fitness and cognition during preadolescence.
\end{abstract}

Keywords: physical activity, executive control, standard deviation, coefficient of variation, reaction time

Recent trends in school policy have minimized opportunities for physical activity (e.g., physical education, recess) from the school day to provide additional classroom time on formal academic topics (Thomas, 2004). Nearly half of American youth 12-21 years of age are not vigorously active on a regular basis, with available data indicating that physical activity declines dramatically during adolescence (USDHHS, 1996), and thus may be insufficient to derive the necessary health benefits (Andersen et al., 2006). Strong and colleagues (2005) conducted a systematic review of the child physical activity and health literature and argued that physically inactive school-age youths may be more likely than their physically active counterparts to develop chronic disease risk factors, though others have argued that this relationship may not be as direct as it appears (see de Geus \& de Moor, 2008 for review). Regardless, researchers have indicated that childhood activity be-

This article was published Online First March 28, 2011.

Chien-Ting Wu, Matthew B. Pontifex, Lauren B. Raine, and Charles H. Hillman, Department of Kinesiology and Community Health, University of Illinois at Urbana-Champaign; Laura Chaddock and Michelle W. Voss, Department of Psychology, University of Illinois at Urbana-Champaign; Arthur F. Kramer, Beckman Institute for Advanced Science and Technology, University of Illinois at Urbana-Champaign.

Support for our research and the preparation of this article was provided by grants from the National Institute on Aging (AG25667 and AG25302) to Arthur F. Kramer and the National Institute of Child Health and Human Development (HD055352) to Charles H. Hillman. No conflicting financial interests exist.

Correspondence concerning this article should be addressed to Charles H. Hillman, Department of Kinesiology \& Community Health, 317 Louise Freer Hall, 906 South Goodwin Avenue, University of Illinois, Urbana, IL 61801. E-mail: chhillma@illinois.edu haviors often continue through the life span (Janz, Dawson, \& Mahoney, 2000), potentially influencing the probability of ill health in later life. Accordingly, overwhelming evidence has emerged to suggest that physical inactivity during childhood is related to decreased health and function across the life span.

In addition to decreases in physical health related to sedentary behaviors, a burgeoning relationship between physical inactivity and decreased cognitive and brain health has emerged in recent years. Meta-analyses have indicated that physical activity has a small, but positive association with perceptual, cognitive, and motor performance (Etnier et al., 1997), and that this relationship may be stronger for school-age children (Sibley \& Etnier, 2003). In adult populations this association appears to be disproportionately larger for tasks or task components that require extensive amounts of cognitive control (Colcombe \& Kramer, 2003; Kramer, Colcombe, McAuley, Scalf, \& Erickson, 2005; Kramer et al., 1999). Cognitive control describes a subset of goal directed, self regulatory cognitive operations involved in the selection, scheduling, and coordination of computational processes that support perception, memory, and action (Meyer \& Kieras, 1997; Norman $\&$ Shallice, 1986). Cognitive control is dependent upon the functional maturation of a network involving the frontal brain regions and in particular the prefrontal cortex (Adleman et al., 2002; Casey, Galvan, \& Hare, 2005; Corbetta, Miezin, Dobmeyer, Shulman, \& Petersen, 1991; Dempster, 1992; Diamond, 1988; Fuster, 1984, 1997; Fassbender et al., 2004; Goldman-Rakic, 1988; Levin et al., 1991; Posner \& Raichle, 1994; Rubia et al., 2000, 2006; Rubia, Smith, Taylor, \& Brammer, 2007; Tamm, Menon, \& Reiss, 2002).

Experimental evidence has suggested that chronic participation in aerobic activity benefits cognition during preadolescent childhood (Buck, Hillman, \& Castelli, 2008; Hinkle, Tuckman \& 
Sampson, 1993; Tuckman \& Hinkle, 1986; see Hillman, Erickson, \& Kramer, 2008 for review). Specifically, Hillman, Castelli, and Buck (2005) found that higher-fit preadolescent children (mean age $=9.6$ years) exhibited shorter reaction time $(\mathrm{RT})$ during performance of a visual discrimination task. However, less evidence exists for the relationship of fitness to RT in children during tasks requiring variable amounts of cognitive control. One such task that has been extensively used to assess cognitive control is the Eriksen flanker task (Eriksen \& Eriksen, 1974), which requires interference control (i.e., one aspect of cognitive control) and has been linked to the ability to inhibit task-irrelevant information in the stimulus environment. Accordingly, this task manipulates the amount of inhibition required to successfully navigate task demands. Using this task, Hillman, Buck, Themanson, Pontifex, and Castelli (2009) examined the relationship between aerobic fitness and cognitive development and found no RT differences as a function of fitness; however, higher-fit children did perform more accurately overall relative to their lower-fit peers. Further support for the relation of fitness to task performance indices of cognitive control stems from adult populations performing flanker paradigms, with shorter RT and greater accuracy consistently observed in more physically active individuals (Hillman et al., 2006; Kramer et al., 1999).

With maturation, preadolescent children continue to increase the speed and efficiency of cognitive control processes, resulting in shorter RT and increased response accuracy (Mezzacappa, 2004; Ridderinkhof, van der Molen, Band, \& Bashore, 1997; Rueda et al., 2004). Specifically, longitudinal research has observed greater performance on specific aspects of cognitive task (i.e., sustain attention) during maturation, with fewer omission errors and shorter RT occurring between 8-13 years in school-age children (Rebok et al., 1997). Further, interference control matures around 8 years of age, resulting in diminished differences in RT and response accuracy from 8 years old through adulthood (Ridderinkhof \& van der Molen, 1995; Ridderinkhof et al., 1997; Rueda et al., 2004).

However, previous studies have suggested that preadolescent children exhibit greater impulsivity than adults, with less modulation of their RT (Davidson, Amso, Anderson, \& Diamond, 2006). Thus, the lack of consensus in RT findings across preadolescent fitness levels (Hillman et al., 2009) might imply that RT is not the best measure to assess the relation of fitness to cognition during preadolescent development. Rather, response accuracy may be a more informative measure when manipulated via task difficulty, providing for a greater range of successful performance within this population.

Accordingly, one means of modulating task difficulty is through the manipulation of stimulus-response compatibility, in addition to the standard manipulation of target-flanker congruency. Such a manipulation would modulate both inhibition and flexibility requirements for successful task performance (Friedman, Nessler, Cycowicz, \& Horton, 2009). Thus, the additional stimulus-response compatibility manipulation allows for additional investigation of cognitive control processes across multiple levels of conflict, and may better inform the relation of fitness to this aspect of cognition. To date, however, only a single study has examined the relation of fitness to cognitive control processes in preadolescent children across multiple levels of conflict (Pontifex et al., in press). Findings from this investigation revealed decreased response ac- curacy for lower-, relative to higher-, fit participants with a selectively larger deficit for the incompatible stimulus-response condition, which requires the greatest amount of cognitive control. With this in mind, the present study sought to extend these findings (Pontifex et al., in press) by examining whether fitness relates to the variability of response execution. That is, beyond the examination of mean performance, measuring the variability of responding provides another means by which to assess cognitive function, with increased intraindividual variability (IIV) related to agerelated cognitive decline, schizophrenia, neurodegenerative disorders, and traumatic brain injury (Mirsky, Pascualvaca, Duncan, \& French, 1999; see MacDonald, Nyberg, \& Bäckman, 2006 for review). With the specific relation on transient changes in behavior, IIV has been distinguished from more enduring change such as learning or development (MacDonald et al., 2006).

In particular, intraindividual standard deviation ( $S D$; Hilborn, Strauss, Hultsch, \& Hunter, 2009; Strauss, MacDonald, Hunter, Moll, \& Hultsch, 2002; Williams, Hultsch, Strauss, Hunter, \& Tannock, 2005 ) and intraindividual coefficient of variation ${ }^{1}$ (CV; Rabbitt, Osman, Moore, \& Stollery, 2001; Strauss et al., 2002; Stuss, Murphy, Malcolm, \& Alexander, 2003) in RT have both been used to assess inconsistencies of responding, and have been applied to the study of mental health and neurological disease. Previous investigations have revealed higher levels of variability in RT for children with attentiondeficit/hyperactivity (Douglas, 1999; Leth-Steensen, Elbaz, \& Douglas, 2000), individuals with mild dementia (Hultsch, Macdonald, Hunter, Levy-Bencheton, \& Strauss, 2000; Strauss et al., 2002) and during nondiseased aging, relative to healthy controls. Greater variability of performance is also observed for task conditions demanding increased amounts of cognitive control (Shammi, Bosman, \& Stuss, 1998; Li \& Lindenberger, 1999; West, Murphy, Armilio, Craik, \& Stuss, 2002). Taken together, these studies of IIV provided unique predictive information related to cognitive functioning independent of mean-level performance (see MacDonald, Li, \& Bäckman, 2009 for review).

However, relative to mean performance (e.g., mean RT), IIV is a relatively recent measure that has been used to study a number of cognitive constructs and thus should be interpreted with caution. That is, MacDonald et al. (2006) has indicated that research on the origins of IIV remains sparse. However, greater IIV has been associated with cognitive processes supported by frontal circuits such as lapses in attentions (Bunce, War, \& Cochrance, 1993) and failures in maintaining cognitive control (West et al., 2002). Further, a growing body of literature suggests a close relationship between the frontal lobes and regions typically involved in motor control (such as the anterior cingulated cortex and striatum) and IIV (Cohen et al., 2010; Murtha et al., 2002; Stuss et al., 2003).

Relative to development, IIV on performance on cognitive control tasks decreases throughout childhood and adolescence ( $\mathrm{Li}$ et

\footnotetext{
${ }^{1}$ It is important to note that $S D$ is based on dispersion from the mean. Thus, a value may deviate more substantially from a large, relative to a small, mean when comparing tasks or groups (Howell, 2010). To resolve this issue, the intraindividual $\mathrm{CV}$ is useful in controlling differences in deviation as each individual's $S D$ is divided by their mean score ( $S D /$ mean $\mathrm{RT}$ ) to scale the $S D$ by the magnitude of the mean RT and allow for comparison of variability across different groups of individuals.
} 
al., 2004; Williams et al., 2005). For example, Williams and colleagues (2005) reported a rapid decrease in RT variability from age six through young adulthood, with a second study indicating that children ages 5 to 8 years exhibited greater variability in RT than young adults aged 16 to 19 years during a cognitive task requiring interference control (Williams, Strauss, Hultsch, \& Hunter, 2007). Accordingly, given the relationship between maturation and behavioral indices of IIV, RT variability may be an important measure in understanding how fitness relates to the maturation of cognitive control processes.

However, the relationship between RT variability and fitness remains unclear. Thus far, only one study has examined the influence of physical activity on cognitive variability in sedentary older adults (Samson et al., 2008). Specifically, 72 active and sedentary young and older adults reported their physical activity behaviors and performed a modified flanker task over five consecutive days of testing. Results indicated that sedentary older adults were more variable within each session across conditions of the flanker task relative to the active adults. Further, sedentary individuals were more variable across testing sessions during the incongruent condition, requiring the greatest amount of cognitive control. Despite these findings, no research to date has examined this relationship in preadolescent children. Thus, the present study aimed to investigate the relation of fitness to RT variability in preadolescent children using a task that modulated cognitive control requirements. Based on (a) previous data demonstrating a positive relationship between fitness and mean RT indices of cognition (Hillman et al., 2005); (b) previous investigations demonstrating a link between aging and other neurological conditions and increased IIV in cognitive functioning (Douglas, 1999; Hultsch, et al., 2000; Leth-Steensen et al., 2000; Strauss et al., 2002); and (c) the link between maturation and decreased IIV, it was expected that lowerfit children would exhibit longer RT and greater variability in intraindividual RT CV.

\section{Method}

\section{Participants}

Forty-eight preadolescent children ( $8-11$ years, 23 female) from the East-Central Illinois region were recruited via flyers and placed into higher $\left(\mathrm{VO}_{2 \max }\right.$ scores above the 70th percentile) or lower $\left(\mathrm{VO}_{2 \max }\right.$ scores below the 30th percentile) fitness groups, based on age-specific norms (Shvartz \& Reibold, 1990). Participants' cardiorespiratory fitness was defined based on the volume of oxygen consumed during maximum capacity $\left(\mathrm{VO}_{2 \max }\right)$ exercise. Table 1 lists demographic and fitness information for the sample. Parents reported that none of the children received special education services related to mental or physical disabilities. All participants and their legal guardians provided written informed assent/consent in accordance with the Institution Review Board at the University of Illinois.

\section{Participant Characteristics}

Data were collected on several factors that have been found to relate with either physical activity participation or cognitive function. Specifically, the Kaufman Brief Intelligence Test (K-BIT; Kaufman \& Kaufman, 1990) was administered by a trained experimenter to obtain a composite IQ scores using measures of crystallized (vocabulary) and fluid (analogies) thinking. In addition, guardians completed a health history questionnaire, the ADHD Rating Scale IV (DuPaul, Power, Anastopoulos, \& Reid, 1998), and reported that their child was free of adverse health conditions, neurologic disorder, attentional disorders, and physical disabilities. Guardians also indicated that their child did not take any medications that influenced central nervous system function and had normal (or corrected to normal) vision. Further, socioeconomic status (SES) was measured by creating a trichotomous index based on three variables: participation in free or reduced-price lunch program at school, the highest level of education obtained by the mother and father, and the number of parents who worked full-time (Birnbaum et al., 2002). Lastly, participants reported pubertal status via the Tanner Staging Scales (Taylor et al., 2001).

\section{Cardiorespiratory Fitness Assessment}

Maximal oxygen consumption $\left(\mathrm{VO}_{2 \max }\right)$ was measured using a computerized indirect calorimetry system (ParvoMedics True Max

Table 1

Participant Demographic and Fitness Data by Fitness Group, Mean \pm SD (Range)

\begin{tabular}{lcc}
\hline \multicolumn{1}{c}{ Measure } & Lower-fit & Higher-fit \\
\hline$n$ & $24(13$ females $)$ & 24 (10 females) \\
Age (years) & $10.1 \pm 0.6(9.0$ to 11.2$)$ & $10.0 \pm 0.6$ (8.9 to 10.9$)$ \\
Tanner & $1.7 \pm 0.5(1$ to 2$)$ & $1.7 \pm 0.5$ (1 to 2$)$ \\
K-BIT composite (IQ) & $113.2 \pm 14.9(84$ to 136$)$ & $115.3 \pm 8.6$ (99 to 130$)$ \\
Socioeconomic Status (SES) & $2.7 \pm 0.6(1$ to 3$)$ & $2.6 \pm 0.6$ (1 to 3$)$ \\
ADHD & $6.3 \pm 4.7(0$ to 19$)$ & $6.9 \pm 4.5$ (0 to 17$)$ \\
$\mathrm{VO}_{2 \text { max }}$ (ml/kg/min) & $35.7 \pm 5.3^{* * *}(19.9$ to 45.1$)$ & $52.6 \pm 4.3^{* * *}$ (46.2 to 63.4$)$ \\
$\mathrm{VO}_{2 \text { max }}$ Percentile & $8.8 \pm 5.3^{* *}(3$ to 20$)$ & $83.3 \pm 4.1^{* *}$ (76 to 94$)$ \\
\hline
\end{tabular}

Note. Tanner- scores indicate that pubertal status was at or below a score of 2 (prepubescent) on the 5-point scale from the Tanner Staging System (Taylor et al., 2001). SES scores reflect a trichotomous index based on participation in free or reduced-price lunch program at school, the highest level of education obtained by the mother and father, and the number of parents who worked full-time (Birnbaum et al., 2002). ADHD = scores on the Attention Deficit Hyperactivity Disorder Rating Scale IV. $\mathrm{VO}_{2 \max }=$ maximum oxygen consumption; $\mathrm{VO}_{2 \max }$ percentile $=$ scores reflect normative values, based on age and sex for $\mathrm{VO}_{2 \max }$ (Shvartz and Reibold, 1990).

*** $p \leq .01$. 
2400) with averages for oxygen uptake $\left(\mathrm{VO}_{2}\right)$ and respiratory exchange ratio (RER) assessed every 20-s. A modified Balke protocol (American College of Sports Medicine [ACSM], 2006) was employed to measure participants' cardiorespiratory fitness. This protocol is recommended and suitable for undertaking graded exercise testing with children (ACSM, 2006). Specifically, following a warm-up period, a motor-driven treadmill was set to a constant speed during the test, while grade increments of $2.5 \%$ occurred every 2 minutes until volitional exhaustion (i.e., the point where participants indicate that they cannot exercise any longer). A Polar heart rate (HR) monitor (Polar WearLink+ 31, Polar Electro, Finland) was used to measure HR. In addition, ratings of perceived exertion (RPE) were measured every 2 minutes using the children's OMNI scale (Utter, Roberson, Nieman, \& Kang, 2002). The children's OMNI scale for RPE uses a numerical scale from 0 to 10 , with each number associated with a pictograph to represent perceived physical effort. Relative peak oxygen consumption was expressed in $\mathrm{ml} / \mathrm{kg} / \mathrm{min}$ and was based upon maximal effort as evidenced by 1) a plateau in oxygen consumption corresponding to an increase of less than $2 \mathrm{ml} / \mathrm{kg} / \mathrm{min}$ despite an increase in workload; 2) a peak heart rate 185 bpm (ACSM, 2006) or a heart rate plateau (Freedson \& Goodman, 1993); 3) RER 1.0 (Bar-Or, 1983); and/or 4) ratings on the children's OMNI scale of perceived exertion 8 (Utter et al., 2002).

\section{Cognitive Task}

Participants completed a modified Eriksen flanker task (Eriksen \& Eriksen, 1974), which required them to respond as quickly and accurately as possible to the direction of a centrally presented target arrow, which was flanked by an array of congruous (e.g., $\ll \ll>$ or $\gg \gg$ ) or incongruous (e.g., $\ll>\ll$ or $\gg<\gg$ ) arrows (Hillman et al., 2006; Pontifex \& Hillman, 2007). Following completion of the stimulus-response compatible condition (described above), participants completed a stimulus-response incompatible condition. In the incompatible flanker condition, participants were presented with similar congruous and incongruous flanker arrays but were instructed to respond as quickly and accurately as possible in the direction opposite that of the centrally presented target arrow (Friedman et al., 2009; Pontifex et al., in press). This task manipulates task difficulty through the modulation of multiple levels of perceptual and response conflict. Each compatibility condition consisted of two blocks of 100 trials with equiprobable congruency and directionality. The stimuli were comprised of $3 \mathrm{~cm}$ tall white arrows that were presented focally on a computer screen with a black background for $200 \mathrm{~ms}$. A fixed interstimulus interval of $1700 \mathrm{~ms}$ was used. For all analyses, individual trials with RTs shorter than 200 ms or longer than 1650 ms were excluded from the data sets.

\section{Laboratory Procedure}

Day 1. Upon arrival to the laboratory, the informed assent and informed consent was completed by participants and their legal guardians, respectively. Next, upon the completion of the questionnaires described above, participants' legal guardians also completed the Physical Activity Readiness Questionnaire (PAR-Q; Thomas, Reading, \& Shephard, 1992), which is a necessary screening tool to ensure safety of the participants prior to exercise.
Prior to the cardiorespiratory fitness assessment, participants were fitted with a Polar HR monitor and had their height and weight measured using a stadiometer and a Tanita BWB-600 digital scale. Following a brief warm-up period, participants exercised at an increasing workload until volitional exhaustion. Upon completion of the cardiorespiratory fitness assessment, participants were given a cool down period and remained in the laboratory until their HR returned to within $10 \mathrm{bpm}$ of their resting HR. Participants with $\mathrm{VO}_{2 \max }$ scores falling above the 70th percentile or below the 30th percentile (Shvartz \& Reibold, 1990) were recruited to participate in the second day of testing.

Day 2. Upon arrival to the laboratory, participants were seated in a sound attenuated testing chamber and given the task instructions prior to each task condition. Forty practice trials were provided and participants' performance was checked before the initiation of testing. When all task conditions were completed, participants were briefed on the purpose of the experiment, and received $\$ 10 /$ hour for their participation.

\section{Statistical Analysis}

Task performance including (1) mean RT; (2) intraindividual $S D$ of RT; (3) intraindividual CV of RT (i.e., $S D /$ mean); and (4) response accuracy were submitted to separate 2 (fitness: higher-fit, lower-fit) $\times 2$ (compatibility: compatible, incompatible) $\times 2$ (congruency: congruent, incongruent) multivariate repeated measures ANOVAs. Post hoc comparisons were conducted using Bonferroni corrected $t$ tests. The family wise alpha level for all tests was set at $p=.05$ prior to Bonferroni corrections.

\section{Results}

Higher-fit participants did not differ significantly from lower-fit participants on any of the demographic variables, $t$ ' $s(1,46) \leq .62$, $p \geq .54$, with the exception of fitness level including both $\mathrm{VO}_{2 \max }$ scores, $t(1,46)=12.2, p<.001$, and $\mathrm{VO}_{2 \max }$ percentile, $t(1$, 46) $=54.8, p<.001($ see Table 1$)$.

\section{Mean of RT}

Analyses indicated a main effect of Congruency with longer RT observed for incongruent $(572.5 \pm 18.3 \mathrm{~ms})$ relative to congruent $(524.0 \pm 15.8 \mathrm{~ms})$ trials, $F(1,46)=49.2, p<.001, \eta^{2}=.52$ (see Figure 1a). This effect was superseded by a Compatibility $\times$ Congruency interaction, $F(1,46)=17.2, p=.001, \eta^{2}=.27$. Decomposition of the Compatibility $\times$ Congruency interaction revealed longer RT for incongruent relative to congruent trails for the compatible condition, $t(1,47)=8.3, p<.001$, and the incompatible condition, $t(1,47)=3.8, p=.001$, (see Table 2$)$. No effects of Fitness or Compatibility were observed, $F$ 's $(1$, $46) \leq 0.7, p \geq .41$, nor did Fitness interact with any variable, $F^{\prime} \mathrm{s}(1,46) \leq 2.2, p \geq .15, \eta^{2} \leq .05$.

\section{Intraindividual $S D$ of $\mathrm{RT}$}

Analyses revealed significant effects of Congruency, $F(1$, 46) $=10.9, p=.002, \eta^{2}=.19$, indicating that congruent $(143.8 \pm 6.9 \mathrm{~ms})$ trials exhibited smaller $S D$ of RT than incongruent $(155.6 \pm 7.1 \mathrm{~ms})$ trials (see Figure $1 \mathrm{~b})$. Further, a main effect of Fitness was observed, $F(1,46)=4.7, p=.04, \eta^{2}=.09$, 

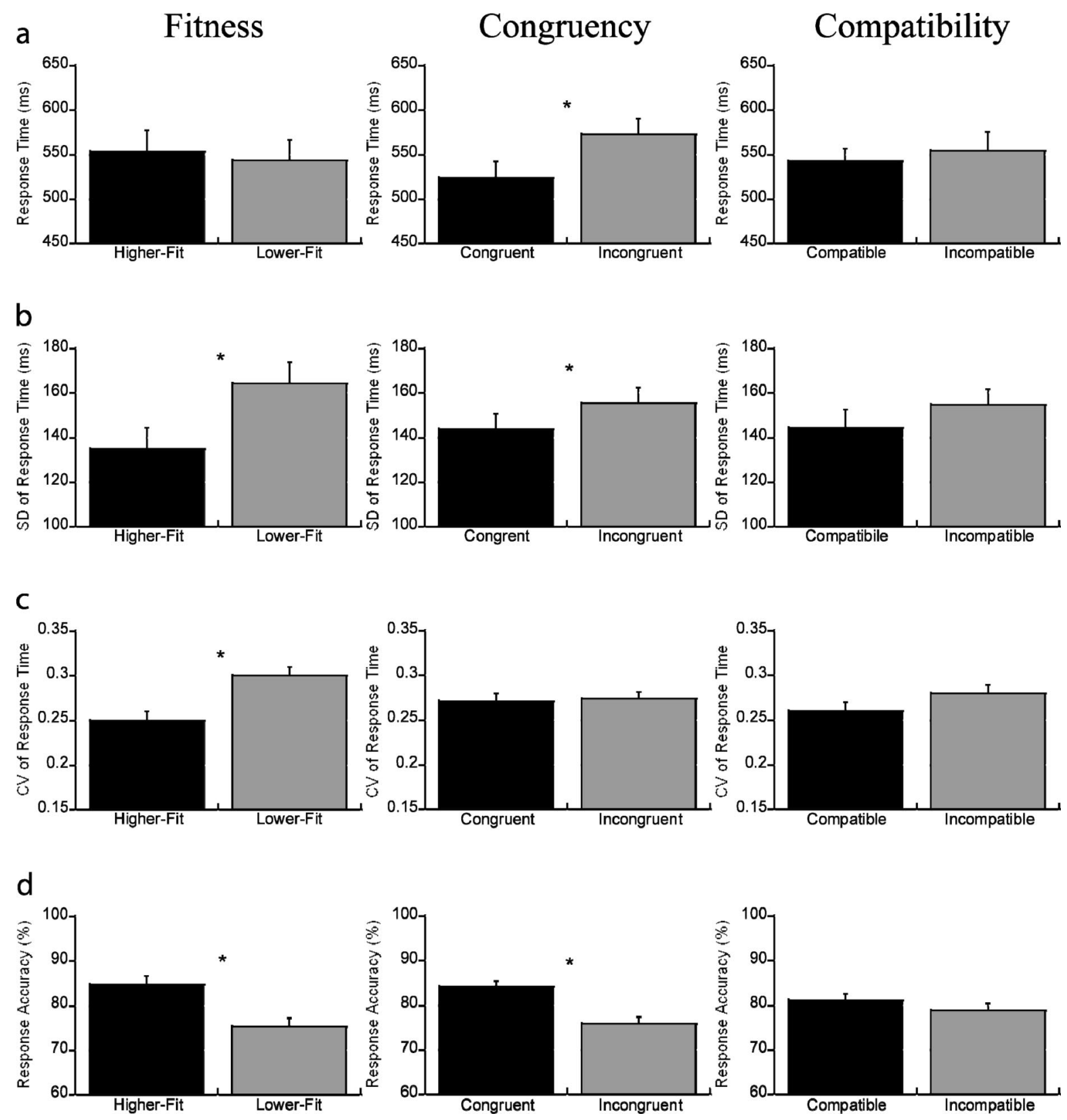

Figure 1. Mean RT (a), SD of RT (b), CV of RT (c), and mean response accuracy (d; +1 SE) for higher- and lower-fit participants collapsed across compatibility and congruency (left), for congruent and incongruent trials of the flanker task collapsed across compatibility and fitness (middle), and for compatible and incompatible conditions collapsed across congruency and fitness (right).

with smaller $S D$ of RT found for higher-fit $(135.0 \pm 9.6 \mathrm{~ms})$ relative to lower-fit (164.4 $\pm 9.6 \mathrm{~ms}$ ) participants (see Figure $1 \mathrm{~b}$ ). No effect of Compatibility was observed, $F(1,46)=2.0, p=.16$, nor did Fitness interact with any variable, $F$ 's $(1,46) \leq 1.26, p \geq$ $.27, \eta^{2} \leq .03$.

\section{Intraindividual CV of RT}

Analyses indicated a Fitness effect, $F(1,46)=12.0, p=.001$, $\eta^{2}=.21$, with larger CV of RT for lower-fit $(.30 \pm .01 \mathrm{~ms})$ relative to higher-fit $(.25 \pm .01 \mathrm{~ms})$ participants (see Figure 1c). No effects of Congruency or Compatibility were observed, $F$ 's $(1$, $46) \leq 2.2, p \geq .14$, nor did Fitness interact with any variable, $F^{\prime} \mathrm{s}(1,46) \leq .32, p \geq .57, \eta^{2} \leq .01$.

\section{Response Accuracy}

Analyses revealed a Congruency effect, $F(1,46)=74.3, p<$ $.001, \eta^{2}=.62$, with greater response accuracy for congruent $(84.3 \pm 1.2 \%)$ relative to incongruent $(75.8 \pm 1.7 \%)$ trials (see 
Table 2

Mean ( $\pm S D)$ Values for Task Performance Measures by Congruency and Response Compatibility for the Flanker Task

\begin{tabular}{|c|c|c|c|c|}
\hline \multirow[b]{2}{*}{ Measure } & \multicolumn{2}{|c|}{ Response compatible condition } & \multicolumn{2}{|c|}{ Response incompatible condition } \\
\hline & Congruent & Incongruent & Congruent & Incongruent \\
\hline \multicolumn{5}{|l|}{ Higher-fit children } \\
\hline $\mathrm{RT}(\mathrm{ms})$ & $503.1 \pm 95.7$ & $579.9 \pm 123.6$ & $524.3 \pm 134.5$ & $565.0 \pm 155.7$ \\
\hline$S D \mathrm{RT}$ & $120.6 \pm 41.1$ & $141.1 \pm 52.1$ & $133.5 \pm 54.7$ & $144.7 \pm 55.0$ \\
\hline CV RT & $.23 \pm .05$ & $0.24 \pm .05$ & $0.25 \pm .06$ & $0.25 \pm .05$ \\
\hline Response accuracy (\% correct) & $89.7 \pm 8.2$ & $79.7 \pm 8.0$ & $87.2 \pm 9.4$ & $82.4 \pm 11.3$ \\
\hline \multicolumn{5}{|l|}{ Lower-fit children } \\
\hline $\mathrm{RT}(\mathrm{ms})$ & $515.7 \pm 96.9$ & $570.9 \pm 100.8$ & $552.7 \pm 140.7$ & $574.1 \pm 160.9$ \\
\hline$S D$ RT & $153.7 \pm 65.3$ & $163.1 \pm 68.9$ & $167.3 \pm 56.6$ & $173.5 \pm 45.3$ \\
\hline CV RT & $.29 \pm .09$ & $0.28 \pm .10$ & $0.30 \pm .07$ & $0.31 \pm .06$ \\
\hline Response accuracy (\% correct) & $84.3 \pm 10.2$ & $71.0 \pm 14.9$ & $75.7 \pm 11.1$ & $70.0 \pm 15.3$ \\
\hline
\end{tabular}

Figure 1d). This effect was superseded by a Compatibility $\times$ Congruency interaction, $F(1,46)=19.2, p<.001, \eta^{2}=.29$, with post hoc tests indicating greater accuracy for incongruent relative to congruent trails for compatible, $t(1,47)=8.1, p<.001$, and incompatible conditions, $t(1,47)=5.5, p<.001$, (see Table 2). Further, a Fitness effect was observed, $F(1,46)=12.5, p=.001$, $\eta^{2}=.21$, with greater response accuracy for higher-fit $(84.8 \pm 1.9 \%)$ relative to lower-fit $(75.2 \pm 1.9 \%)$ participants (see Figure 1d). No effect of Compatibility was observed, $F(1$, $40)=1.61, p=.21$, nor did Fitness interact with any variable, $F^{\prime} \mathrm{s}(1,40) \leq 3.56, p \geq .07, \eta^{2} \leq .08$.

Given that the results revealed the relation of fitness to response accuracy and IIV, additional Pearson product-moment correlations were to further examine this relationship. For this analysis, accuracy and IIV variables were collapsed across Compatibility and Congruency. Results indicated that response accuracy was negatively correlated with $S D$ of RT $(r=-.61, p<.001)$ and CV of RT $(r=-.68$, $p<.001$ ), indicating that higher accuracy was related to decreased IIV. In addition, $\mathrm{VO}_{2 \max }$ scores were positively correlated with response accuracy $(r=.44, p=.002)$, negatively correlated with $S D$ of RT $(r=-.40, p=.005)$, and negatively correlated with CV of RT $(r=-.48, p=.001)$. Similarly, $\mathrm{VO}_{2 \max }$ percentile was positively correlated with response accuracy $(r=.46, p=.001)$, and negatively correlated with $S D$ of RT $(r=-.32, p=.03)$, and CV of RT $(r=$ $-.46, p=.001)$.

\section{Discussion}

The findings reported herein indicate that higher aerobic fitness was related to more accurate and less variable cognitive performance in preadolescent children using a task that required variable amounts of interference control, one aspect of cognitive control. Specifically, higher- and lower-fit children exhibited the expected increase in mean RT and decrease in response accuracy to incongruent compared to congruent trials. We found interesting that the $S D$ of RT further reflected the expected congruency effect with increased response variability during incongruent, as compared to congruent, trials. However, when fitness was considered, higher-fit children exhibited lower $S D$ of RT, lower $\mathrm{CV}$ of RT, and higher response accuracy compared to lower-fit children regardless of task condition, suggesting that fitness may be related to overall performance and consistency in performance during tasks requir- ing variable amounts of cognitive control. Further, correlational analyses supported the relation of fitness to response accuracy and IIV; a relationship that was not observed for mean RT. Taken together, IIV might be a robust index to examine the relationship between fitness and cognitive function in children independent of mean-level performance.

Replicating previous research (Mezzacappa, 2004; Ridderinkhof \& van der Molen, 1995; Hillman et al., 2009), preadolescent children, regardless of fitness level, exhibited shorter RT and increased response accuracy on congruent relative to incongruent trials across compatibility conditions, suggesting that task conditions requiring greater amounts of interference control are associated with decrements in task performance. In addition to the robust findings for mean RT, performance variability measures ( $S D$ of RT) replicate the findings of West et al. (2002) who observed increased RT variability during task conditions requiring the increased recruitment of cognitive control relative to less demanding task conditions across the life span.

The current study also replicates previous investigations demonstrating a beneficial relation between fitness and cognitive control in preadolescent children (Hillman et al., 2009). Specifically, the findings indicated increased response accuracy for higher-fit children across task conditions, compared to lower-fit children, with no fitness-related differences observed for mean RT. Taken together, these findings suggest that in a preadolescent population, fitness may be associated with general improvements in cognition during tasks requiring variable amounts of cognitive control.

Novel to the present investigation was the assessment of measures of IIV in preadolescent children, which showed increased RT variability, as demonstrated by a fitness effect for the $S D$ of RT, with lower-fit participants exhibiting greater variability. Further, greater variability was observed for lower-fit participants as measured by the intraindividual RT CV, in which each individual's $S D$ of RT was divided by his or her own mean score to account for mean-level group differences. Consistent with the findings of Samson et al. (2008), which reported that sedentary older adults were more variable than their active peers, the present data suggests that higher fitness levels may relate to increased response accuracy and more response stability in preadolescent children. Accordingly, given the relationship between response variability and normal development in childhood (Williams et al., 2005), higher amounts of fitness may relate to 
enhanced neural maturation, with systematic changes in brain morphology, gray matter density, and synaptic alterations resulting in improved neural efficiency and decrease noise in cognitive functioning (Gogtay et al., 2004).

There are a number of mechanisms that have been identified, which may account for the observed fitness-related differences in response variability. For instance, human and nonhuman animal research has indicated that aerobic exercise can facilitate a variety of aspects of cognitive function (see Hillman et al., 2008 for review). Specifically, MRI studies in humans have found that higher levels of fitness and fitness improvements resulting from aerobic exercise training were associated with larger volumes of prefrontal and temporal gray matter (Colcombe et al., 2004, 2006) as well as anterior white matter (Gordon et al., 2008; Mark et al., 2007) volumes. Further, studies of neural lesions in frontal gray and white matter, which share a robust association with increased IIV, lend support for our current findings (see MacDonald et al., 2009 for review). Given that the reported decreases in IIV during development (Williams et al., 2005) have been linked to systematic changes in brain morphology, particularly in the frontal cortex (Gogtay et al., 2004), it is likely that fitness may play a role in mediating alterations in frontal gray and white matter, resulting in decreased IIV. In addition to the changes observed in frontal gray and white matter in human studies, nonhuman animal research has linked exercise training with structural changes in basal ganglia. For example, Aguiar, Speck, Prediger, Kapczinski, and Pinho (2008) found that exercise training in mice contributed to increases in the production and secretion of striatal brain-derived neurotrophic factor (BDNF), and Marques et al. (2008) observed increases in striatal dopamine. Most recently, Chaddock et al. (in press) used a flanker task to investigate the relationship between aerobic fitness and dorsal and ventral striatal volumes in preadolescent children and suggested that greater aerobic fitness was related to greater dorsal striatal volumes. Taken together, findings across species have suggested that higher fitness is associated with enhanced cognitive control and may account for the observed fitness-related differences in response variability.

In sum, these findings suggest that higher preadolescent aerobic fitness is related to decreased response variability during cognitive control processes. Further, fitness was associated with better response accuracy, whereas no differences were observed for response speed. It is important to note, however, a number of limitations to the current study. First, the cross-sectional design yields the possibility that the observed fitness-related differences, could have resulted from some other (or combination of other) factors. However, this possibility was minimized by the collection of other demographic variables (e.g., IQ, SES) that have been related to fitness or cognition, but does not exclude the possibility that a selection bias may have occurred. Accordingly, randomized control interventions are needed to establish a causal relationship between fitness and response variability in children. The current dataset, however, extends this area of research by suggesting that IIV might be a useful task performance measure to examine the relationship between fitness and the maturation of cognitive function during preadolescence. Such findings add support for the beneficial relation of fitness to cognitive and brain health and function, and may have implications for scholastic performance.

\section{References}

Adleman, N. E., Menon, V., Blasey, C. M., White, C. D., Warsofsky, I. S., Glover, G. H., \& Reiss, A. L. (2002). A developmental fMRI study of the Stroop color-word task. NeuroImage, 16, 61-75.

Aguiar, A. S., Speck, A. E., Prediger, R. D., Kapczinski, F., \& Pinho, R. A. (2008). Downhill training upregulates mice hippocampal and striatal brain-derived neurotrophic factor levels. Journal of Neural Transmission, 115, 1251-1255.

American College of Sports Medicine. (2006). ACSM's guidelines for exercise testing and prescription (7th ed.). New York: Lippincott Williams \& Wilkins.

Andersen, L. B., Harro, M., Sardinha, L. B., Froberg, K., Ekelund, U., Brage, S., \& Anderssen, S. A. (2006). Physical activity and clustered cardiovascular risk in children: A cross-sectional study (The European Youth Heart Study). Lancet, 368, 299-304.

Bar-Or, O. (1983). Pediatric sports medicine for the practitioner: From physiologic principles to clinical applications. New York: SpringerVerlag.

Birnbaum, A. S., Lytle, L. A., Murray, D. M., Story, M., Perry, C. L., \& Boutelle, K. N. (2002). Survey development for assessing correlates of young adolescents' eating. American Journal of Health Behavior, 26, 284-295.

Buck, S. M., Hillman, C. H., \& Castelli, D. M. (2008). The relation of aerobic fitness to Stroop task performance in preadolescent children. Medicine \& Science in Sports \& Exercise, 40, 166-172.

Bunce, D. J., Warr, P. B., \& Cochrance, T. (1993). Blocks in choice responding as a function of age and physical fitness. Psychology and Aging, 8, 26-33.

Casey, B. J., Galvan, A., \& Hare, T. A. (2005). Changes in cerebral functional organization during cognitive development. Current Opinions in Neurobiology, 15, 239-244.

Chaddock, L., Erickson, K. I., Prakash, R. S., Kim, J. S., Voss, M. W., VanPatter., ... Kramer, A. F. (in press). A neuroimaging investigation of the association between aerobic fitness, hippocampal volume and memory performance in preadolescent children. Brain Research.

Cohen, J. R., Asarnow, R. F., Sabb, F. W., Bilder, R. M., Bookheimer, S. Y., Barbara, J. K., . . Poldrack, R. A. (2010). Decoding developmental differences and individual variability in response inhibition through predictive analyses across individuals. Frontiers in Human Neuroscience, 4, 1-12.

Colcombe, S. J., Erickson, K. I., Scalf, P. E., Kim, J. S., Prakash, R., McAuley, E., ... Kramer, A. F. (2006). Aerobic exercise training increases brain volume in aging humans. The Journals of Gerontology Series A, Biological Sciences and Medical Sciences, 61, 1166-1170.

Colcombe, S. J., \& Kramer, A. F. (2003). Fitness effects on the cognitive function of older adults: A meta-analytic study. Psychological Science, 14, 125-130.

Colcombe, S. J., Kramer, A. F., Ericksen, K. I., Scalf, P., McAuley, E., Cohen, N. J., . . Elavsky, S. (2004). Cardiovascular fitness, cortical plasticity, and aging. Proceedings of the National Academy of Sciences, USA, 101, 3316-3321.

Corbetta, M., Miezin, F., Dobmeyer, S., Shulman, G., \& Petersen, S. (1991). Selective and divided attention during visual discriminations of shape, color, and speed: Functional anatomy by positron emission tomography. Journal of Neuroscience, 11, 2383-2402.

Davidson, M. C., Amso, D., Anderson, L. C., \& Diamond, A. (2006). Development of cognitive control and executive functions from 4-13 years: Evidence from manipulation of memory, inhibition, and task switching. Neuropsychologia, 44, 2037-2078.

De Geus, E. J. C., \& De Moor, M. H. M. (2008). A genetic perspective on the association between exercise and mental health. Mental Health and Physical Activity, 1, 53-61. 
Dempster, F. N. (1992). The rise and fall of the inhibitory mechanism: Toward a unified theory of cognitive development and aging. Developmental Review, 12, 45-75.

Diamond, A. (1988). Abilities and neural mechanisms underlying A-not-B performance. Child Development, 59, 523-527.

Douglas, V. I. (1999). Cognitive control processes in attention deficit hyperactivity disorder. In: H. C. Quay, \& A. E. Hogan (Eds.), Handbook of disruptive behavior disorders (pp. 105-138). New York: Plenum Press.

DuPaul, G. J., Power, T. J., Anastopoulos, A. D., \& Reid, R. (1998). ADHD Rating Scale-IV: Checklists, norms, and clinical interpretation. New York: The Guilford Press.

Eriksen, C. W., \& Eriksen, B. A. (1974). Effects of noise letters upon the identification of a target letter in a non-search task. Perception and Psychophysics, 16, 143-149.

Etnier, J. R., Salazar, W., Landers, D. M., Petruzzello, S. J., Han, M., \& Nowell, P. (1997). The influence of physical fitness and exercise upon cognitive functioning: A meta- analysis. Journal of Sport and Exercise Psychology, 19, 249-277.

Fassbender, C., Murphy, K., Foxe, J., Wylie, G., Javitt, D., Robertson, I., \& Garavan, H. (2004). A topography of executive functions and their interactions revealed by functional magnetic resonance imaging. Cognitive Brain Research, 20, 132-143.

Freedson, P. S., \& Goodman, T. L. (1993). Measurement of oxygen consumption. In T. W. Rowland (Ed.), Pediatric laboratory exercise testing: Clinical guidelines (pp. 91-113). Champaign, IL: Human Kinetics.

Friedman, D., Nessler, D., Cycowicz, Y., \& Horton, C. (2009). Development of and change in cognitive control: A comparison of children, young adults, and older adults. Cognitive, Affective, and Behavioral Neuroscience, 9, 91-102.

Fuster, J. M. (1984). Functional relationship between inferotemporal and prefrontal cortex. In F. Reinoso-Suárez \& C. Ajmone-Marsan (Eds.), Cortical integration: Basic, archicortical, and cortical association levels of neural integration (Vol. 2, pp. 341-352). New York: Raven Press.

Fuster, J. M. (1997). The prefrontal cortex and the cognitive foundation of orderly action. In G. W. Mazur (Ed.), Twenty year commemoration to the life of A. R. Luria, (pp. 45-60). New York: Semeneko Foundation.

Gogtay, N., Giedd, J. N., Lusk, L., Hayashi, K. M., Greenstein, D., Vaituzis, A. C., ... Thompson, P. M. (2004). Dynamic mapping of human cortical development during childhood through early adulthood. Proceedings of the National Academy of Sciences, USA of the United States of America, 101, 8174-8179.

Goldman-Rakic, P. S. (1988). Topography of cognition: Parallel distributed networks in primate association cortex. Annual Review of Neuroscience, 11, 137-156.

Gordon, B., Rykhlevskaia, E., Brumback, C., Lee, Y., Elavsky, S., Konopack, J., ... Fabiani, M. (2008). Neuroanatomical correlates of aging, cardiopulmonary fitness level, and education. Psychophysiology, 45, $825-838$.

Hilborn, J. V., Strauss, E., Hultsch, D., \& Hunter, M. A. (2009). Intraindividual variability across cognitive domains: Investigation of dispersion levels and performance profiles in older adults. Journal of Clinical \& Experimental Neuropsychology, 31, 412-424.

Hillman, C. H., Buck, S. M., Themanson, J. R., Pontifex, M. B., \& Castelli, D. M. (2009). Aerobic fitness and cognitive development: Event-related brain potential and task performance indices of executive control in preadolescent children. Developmental Psychology, 45, 114-129.

Hillman, C. H., Castelli, D. M., \& Buck, S. M. (2005). Aerobic fitness and neurocognitive function in healthy preadolescent children. Medicine \& Science in Sports \& Exercise, 37, 1967-1974.

Hillman, C. H., Erickson, K. I., \& Kramer, A. F. (2008). Be smart, exercise your heart: Exercise effects on brain and cognition. Nature Reviews Neuroscience, 9, 58-65.
Hillman, C. H., Motl, R. W., Pontifex, M. B., Posthuma, D., Stubbe, J. H., Boomsma, D. I., \& de Geus, E. J. C. (2006). Physical activity and cognitive function in a cross-section of younger and older communitydwelling individuals. Healthy Psychology, 25, 678-687.

Hinkle, J. S., Tuckman, M. W., \& Samson, J. P. (1993). The psychology, physiology, creativity of middle school aerobic exercisers. Elementary School Guidance and Counseling, 28, 133-145.

Howell, D. C. (2010). Statistical methods for psychology. (7th ed.). Belmont, CA: Duxbury Press.

Hultsch, D. F., MacDonald, S. W. S., Hunter, M., Levy-Bencheton, J., \& Strauss, E. (2000). Intraindividual variability in cognitive performance in the elderly: Comparison of adults with mild dementia, adults with arthritis, and healthy adults. Neuropsychology, 14, 588-598.

Janz, K. F., Dawson, J. D., \& Mahoney, L. T. (2000). Tracking physical fitness and physical activity from childhood to adolescence: The Muscatine study. Medicine and Science in Sports and Exercise, 32, 12501257.

Kaufman, A. S., \& Kaufman, N. L. (1990). Kaufman Brief Intelligence Test manual. Circle Pines, MN: American Guidance Service.

Kramer, A. F., Colcombe, S. J., McAuley, E., Scalf, P. E., \& Erickson, K. I. (2005). Fitness, aging and neurocognitive function. Neurobiology of Aging, 26124-26127.

Kramer, A. F., Hahn, S., Cohen, N., Banich, M., McAuley, E., Harrison, C., ... Colcombe, A. (1999). Aging, fitness, and neurocognitive function. Nature, 400, 418-419.

Leth-Steensen, C., King Elbaz, Z., \& Douglas, V. I. (2000). Mean response time, variability, and skew in the responding of ADHD children: A response time distributional approach. Acta Psychologica, 104, 167190.

Levin, H. S., Culhane, K. A., Hartmann, J., Evankovich, K., Mattson, A. J., Harward, H., ... Fletcher, J. M. (1991). Developmental changes in performance on tests of purported frontal lobe Functioning. Developmental Neuropsychology, 7, 377-395.

Li, S., \& Lindenberger, U. (1999). Cross-level unification: A computational exploration of the link between deterioration of neurotransmitter systems and dedifferentiation of cognitive abilities in old age. In L. G. Nilsson \& H. J. Markowitsch (Eds.), Cognitive neuroscience of memory (pp. 103-146). Seattle: Hogrefe \& Huber.

Li, S., Lindenberger, U., Hommel, B., Aschersleben, G., Prinz, W., \& Baltes, P. B. (2004). Transformations in the couplings among intellectual abilities and constituent cognitive processes across the life span. Psychological Science, 15, 155-163.

MacDonald, S. W., Li, S. C., \& Bäckman, L. (2009). Neural underpinnings of within-person variability in cognitive functioning. Psychology and Aging, 24, 792-808.

MacDonald, S. W., Nyberg, L., \& Bäckman, L. (2006). Intra-individual variability in behavior: Links to brain structure, neurotransmission and neuronal activity. Trends in Neuroscience, 29, 474-480.

Marks, B. L., Madden, D. J., Bucur, B., Provenzale, J. M., White, L. E., Cabeza, R., \& Huettel, S. A. (2007). Role of aerobic fitness and aging in cerebral white matter integrity. Annals of the New York Academy of Sciences, 1097, 171-174.

Marques, E., Vasconcelos, F., Rolo, M. R., Pereira, F. C., Silva, A. P., Macedo, T. R., \& Ribeiro, C. F. (2008). Influence of chronic exercise on the amphetamine-induced dopamine release and neurodegeneration in the striatum of the rat. Annals of the New York Academy of Sciences, 1139, 222-231.

Meyer, D. E., \& Kieras, D. E. (1997). A computational theory of executive cognitive processes and multiple task performance: Pt. 1. Basic mechanisms. Psychological Review, 104, 3-65.

Mezzacappa, E. (2004). Alerting, orienting, and executive attention: Developmental properties and sociodemographic correlates in an epidemiological sample of young, urban children. Child Development, 75, 1373 1386. 
Mirsky, A. F., Pascualvaca, D. M., Duncan, C. C., \& French, L. M. (1999). A model of attention and its relation to ADHD. Mental Retardation \& Developmental Disabilities Research Reviews, 5, 169-176.

Murtha, S., Cismaru, R., Waechter, R., \& Cheritkow, H. (2002). Increased variability accompanies frontal lobe damages in dementia. Journal of the International Neuropsychological Society, 8, 360-372.

Norman, W., \& Shallice, T. (1986). Attention to action. In R. J. Davidson, G. E. Schwartz, \& D. Shapiro (Eds.), Consciousness and self regulation: Advances in research and theory (Vol. 4, pp. 1-18). New York: Plenum Press.

Pontifex, M. B., \& Hillman, C. H. (2007). Neuroelectric and behavioral indices of interference control during acute cycling. Clinical Neurophysiology, 118, 570-580.

Pontifex, M. B., Raine, L. B., Johnson, C. R., Chaddock, L., Voss, M. W., Cohen, N. J., ... Hillman, C. H. (in press). Cardiorespiratory fitness and the flexible modulation of cognitive control in preadolescent children. Journal of Cognitive Neuroscience.

Posner, M. I., \& Raichle, M. E. (1994). Images of mind. New York: Freeman.

Rabbitt, P., Osman, P., Moore, B., \& Stollery, B. (2001). There are stable individual differences in performance variability, both from moment to moment and from day to day. The Quarterly Journal of Experimental Psychology, 54A, 981-1003.

Rebok, G. W., Smith, C. B., Pascualvaca, D. M., Mirsky, A. F., Anthoney, B. J., \& Kellam, S. G. (1997). Developmental changes in attentional performance in urban children from eight to thirteen years. Child Neuropsychology, 3, 28-46.

Ridderinkhof, K. R., \& Van der Molen, M. W. (1995). A psychophysiological analysis of developmental differences in the ability to resist interference. Child Development, 66, 1040-1056.

Ridderinkhof, K. R., Van der Molen, M. W., Band, G. P. H., \& Bashore, T. R. (1997). Sources of interference from irrelevant information: A developmental study. Journal of Experimental Child Psychology, 65, 315-341.

Rubia, K., Overmeyer, S., Taylor, E., Brammer, M., Williams, S. C., Simmons, A., . . Bullmore, E. T. (2000). Functional frontalisation with age: Mapping neurodevelopmental trajectories with fMRI. Neuroscience and Biobehavioral Reviews, 24, 13-19.

Rubia, K., Smith, A. B., Taylor, E., \& Brammer, M. (2007). Linear age-correlated functional development of right inferior fronto-striatocerebellar networks during response inhibition and anterior cingulate during error-related processes. Human Brain Mapping, 28, 1163-1177.

Rubia, K., Smith, A. B., Woolley, J., Nosarti, C., Heyman, I., Taylor, E., \& Brammer, M. (2006). Progressive increase of frontostriatal brain activation from childhood to adulthood during event-related tasks of cognitive control. Human Brain Mapping, 27, 973-993.

Rueda, M., Fan, J., McCandliss, B., Halparin, J., Gruber, D., Lercari, L., \& Posner, M. I. (2004). Development of attentional networks in childhood. Neuropsychologia, 42, 1029-1040.

Samson, J. M., Sosnoff, J. J., Buck, S. M., Pontifex, M. B., Themason, J. R., \& Hillman C. H. (2008, June). Aerobic exercise training and intra-individual cognitive variability in older adults. American College of Sports Medicine Annual Meeting, Indianapolis, IN.

Shammi, P., Bosman, E., \& Stuss, D. T. (1998). Aging and variability in performance. Aging, Neuropsychology, and Cognition, 5, 1-13.
Shvartz, E., \& Reibold, R. C. (1990). Aerobic fitness norms for males and females aged 6 to 75 years: A review. Aviation, Space, and Environmental Medicine, 61, 3-11.

Sibley, B. A., \& Etnier, J. L. (2003). The relationship between physical activity and cognition in children: A meta-analysis. Pediatric Exercise Science, 15, 243-256.

Strauss, E., MacDonald, S. W., Hunter, M., Moll, A., \& Hultsch, D. F. (2002). Intraindividual variability in cognitive performance in three groups of older adults: Cross-domain links to physical status and selfperceived affect and beliefs. Journal of the International Neuropsychological Society, 8, 893-906.

Strong, W. B., Malina, R. M., Blimkie, C. J., Daniels, S. R., Dishman, R. K., Gutin, B., . . Trudeau, F. (2005). Evidence based physical activity for school-age youth. Journal of Pediatrics, 146, 732-737.

Stuss, D. T., Murphy, K. J., Binns, M. A., \& Alexander, M. P. (2003). Staying on the job: The frontal lobes control individual performance variability. Brain, 126, 2363-2380.

Tamm, L., Menon, V., \& Reiss, A. L. (2002). Maturation of brain function associated with response inhibition. Journal of the American Academy of Child and Adolescent Psychiatry, 41, 1231-1238.

Taylor, S. J., Whincup, P. H., Hindmarsh, P. C., Lampe, F., Odoki, K., \& Cook, D. G. (2001). Performance of a new pubertal self-assessment questionnaire: A preliminary study. Pediatric and Perinatal Epidemiology, 15, 88-94.

Thomas, K. T. (2004). Riding to the rescue while holding on by a thread: Physical activity in the schools. Quest, 56, 150-170.

Thomas, S., Reading, J., \& Shephard, R. J. (1992). Revision of the Physical Activity Readiness Questionnaire (PAR-Q). Canadian Journal of Sport Sciences, 17, 338-345.

Tuckman, B. W., \& Hinkle, J. S. (1986). An experimental study of the physical and psychological effects of aerobic exercise on schoolchildren. Health Psychology, 5, 197-207.

U.S. Departments of Health and Human Services (USDHHS). (1996). Physical activity and health: A report of the surgeon general. Washington, DC: U.S. Government Printing Office.

Utter, A. C., Roberson, R. J., Nieman, D. C., \& Kang, J. (2002). Children's OMNI scale of perceived exertion: Walking/running evaluation. Medicine and Science in Sports and Exercise, 34, 139-144.

West, R., Murphy, K. J., Armilio, M. L., Craik, F. I. M., \& Stuss, D. T. (2002). Lapses of intention and performance variability reveal agerelated increases in fluctuations of executive control. Brain and Cognition, 49, 402-419.

Williams, B. R., Hultsch, D. F., Strauss, E. H., Hunter, M. A., \& Tannock, R. (2005). Inconsistency in reaction time across the life span. Neuropsychology, 19, 88-96.

Williams, B. R., Strauss, E. H., Hultsch, D. F., \& Hunter, M. A. (2007). Reaction time inconsistency in a Spatial Stroop Task: Age-related differences through childhood and adulthood. Aging, Neuropsychology \& Cognition, 14, 417-439.

Received May 11, 2010

Revision received November 5, 2010 Accepted November 10, 2010 